\title{
The Renal Lesion Associated with Hemoglobinemia: A Study of the Pathogenesis of the Excretory Defect in the Rat*
}

\author{
JoH N R. JAENIKE $\dagger$ \\ (From the Department of Medicine, University of Rochester School of Medicine and \\ Dentistry, Rochester, N.Y.)
}

\begin{abstract}
Summary. The role of renal ischemia in the pathogenesis of the renal failure produced by hemoglobin injection in the rat is evaluated. The data indicate that in the initial hours of this lesion renal blood flow is consistently reduced and that during its subsequent evolution blood flow rises towards normal levels, in some animals, while inulin clearance remains severely depressed. Volume expansion during the initial stage of the lesion may effect a rise in renal blood flow to normal levels with little effect on inulin clearance rate, further demonstrating the relative lack of dependence of the excretory defect on concomitant renal ischemia. These observations indicate that renal ischemia is probably a necessary factor in the initial production of the lesion; that it persists during its initial phase, up to 24 hours in most rats ; and that, although it may contribute to the observed excretory defect, it is not the predominant etiologic factor.

Other functional data indicate that renal blood is perfusing nephrons in which the excretory capacity is impaired but which retain the ability to extract Diodrast from the peritubular capillaries. This functional pattern indicates an excretory defect secondary either to intratubular obstruction or to a primary reduction of glomerular filtration rate of undefined etiology. The morphological findings of numerous dense intratubular hemoglobin casts and, in the well-perfused kidney, dilatation of proximal tubules, are suggestive of an obstructive lesion. However, the data do not conclusively distinguish between these two pathogenetic mechanisms.
\end{abstract}

\section{Introduction}

Acute renal failure in man occurs in a variety of clinical settings, reflecting the diversity of basic etiologic factors implicated in this syndrome. The precise alterations in discrete renal functions that lead to the excretory failure characteristic of this syndrome remain unknown. However, knowl-

* Submitted for publication August 1, 1966; accepted November 10, 1966.

This work was supported by U. S. Public Health Service research grant $\mathrm{HE} 07966$ from the National Heart Institute.

$\dagger$ Recipient of National Institutes of Health Career Development Award HE 4526.

Address requests for reprints to Dr. John R. Jaenike, the University of Rochester School of Medicine and Dentistry, 260 Crittenden Blvd., Rochester, N. Y. 14620. edge in this area is advancing as refined techniques are applied to the study of lesions induced in experimental animals, which may be analogous to those occurring in man (1-3). The present study deals with an attempt to produce such a model by inducing acute renal failure associated with hemoglobinemia in the rat. The mode of production of this lesion, its functional evolution as defined by serial studies of inulin clearance rate, and certain of its morphological features have been previously described $(4,5)$. These initial observations gave rise to the hypotheses that renal ischemia was an important factor in the initial stages of this lesion and that nephron obstruction by intratubular precipitates of hemoglobin was primarily responsible for the more 
protracted diminution in excretory function observed in these animals. These hypotheses have been tested in the present study by measuring renal blood flow at various stages of the lesion, from several hours to 7 days after hemoglobin injection, and relating the results to inulin clearance rates and structural changes in the kidney. We have also investigated the effect of interventions that augment renal blood flow in order to define further the relationship between blood flow and inulin clearance rate. The data have generally supported the above stated hypotheses. Renal ischemia appears to be a constant finding in the initial hours of this lesion, and it usually persists to 24 hours after its inception. However, normal renal blood may coexist with marked depression of inulin clearance, either as a result of induced volume expansion or during the natural evolution of the lesion, indicating that factors other than reduced perfusion must be implicated in the pathogenesis of the excretory defect. These observations and other functional and structural data suggest that tubular obstruction by hemoglobin casts is an important factor in the reduced renal excretory function observed in this lesion.

\section{Methods}

Experiments were performed on female Wistar rats, Rochester strain, weighing from 150 to $250 \mathrm{~g}$. Animals were fed Purina chow and allowed water ad libitum, except during the dehydration period before hemoglobin administration. Homologous hemoglobin solution was prepared and administered intravenously, as previously described (4). This preparation was virtually free of stroma upon examination by phase microscopy, and its administration was associated with no significant mortality. Unless otherwise indicated, all rats in this study were injected with hemoglobin solution during ether anesthesia after 72 hours of water deprivation. Water was withheld for 1 to 2 hours after hemoglobin injection; water and food were then allowed ad libitum.
Renal blood flow was measured by the whole blood clearance of Diodrast- ${ }^{131} \mathrm{I}$, corrected for renal extraction by sampling from a catheter in the renal vein. For this purpose an Intramedic $\mathrm{PE} 50$ polyethylene catheter was introduced into the left ovarian vein, through which it was threaded until the tip protruded into the lumen of the renal vein. The catheter was then tied in place, and the left adrenal vein, the sole other source of nonrenal blood entering the renal vein, was ligated. The end of the catheter was then brought out through the midline abdominal incision, and the wound was closed with clips. Blood was collected from the renal vein catheter into tubes containing powdered heparin by gentle compression on the upper abdomen over the vena cava. No means were available for detecting reflux of blood from vena cava into renal vein and its subsequent collection; we minimized this possibility by assuring that the tip of the renal catheter lay at least $5 \mathrm{~mm}$ from the vena cava. In addition, the following evidence indicates that contamination by vena caval blood was infrequent, if it ever occurred : 1) A narrow range of Diodrast extraction ratios was observed in a large number of control experiments (Table I). 2) Duplicate ratios in individual experiments were in generally close agreement. The higher value exceeded the lower by a mean of $4.2 \%$ in 29 control rats and by $7.6 \%$ in 37 rats studied after hemoglobin injection. 3) In five normal rats serial Diodrast extraction ratios were determined, the last with a clamp on the left renal vein proximal to the site of sampling. In no instance was the last extraction ratio higher than the mean of the preceding two values, indicating that the latter were not suppressed by mixture of vena caval and renal venous blood during sampling.

In the initial experiments on normal rats, the renal vein catheter was implanted 3 to 7 days before the clearance study. In these animals the tip of the catheter was heat-sealed and ligated to the rectus sheath immediately under the abdominal incision. At the time of clearance study, it was brought to the exterior through a small skin incision, and blood samples were collected as previously described. This technique proved relatively successful for control studies on normal rats. In rats subjected to 72 hours of dehydration and injected with hemoglobin, patency of the catheter persisted only occasionally, resulting in a high percentage of experimental failures. Consequently, in the hemoglobin-injected animals under pentobarbital anesthesia, the renal vein was cathe-

TABLE I

Renal functions in control animals*

\begin{tabular}{|c|c|c|c|c|c|c|}
\hline Group & $\begin{array}{l}\text { No. of } \\
\text { rats }\end{array}$ & $E_{\mathbf{D}}$ & $\mathrm{C}_{\mathrm{In}}$ & $C_{D}$ & $\mathrm{C}_{I_{n}} / \mathrm{CD}_{\mathrm{D}}$ & $\mathrm{U}_{\mathrm{In}} / \mathrm{P}_{\mathrm{In}}$ \\
\hline & & & $\mathrm{ml} / \mathrm{min} / 100 \mathrm{~g}$ & $\mathrm{ml} / \mathrm{min} / 100 \mathrm{~g}$ & & \\
\hline Previously operated, normal rats & 11 & $0.550 \pm 0.015 \dagger$ & $0.846 \pm 0.050$ & $4.00 \pm 0.23$ & $0.215 \pm 0.014$ & $376 \pm 27$ \\
\hline Saline control, $¥ 3$ to 5 hours after injection & 9 & $0.567 \pm 0.016$ & $0.771 \pm 0.083$ & $3.78 \pm 0.40$ & $0.209 \pm 0.005$ & $326 \pm 17$ \\
\hline Saline control, $¥ 24$ hours after injection & 9 & $0.558 \pm 0.017$ & $0.817 \pm 0.092$ & $4.09 \pm 0.53$ & $0.209 \pm 0.010$ & $391 \pm 59$ \\
\hline
\end{tabular}

* Abbreviations: $E_{D}=$ renal extraction ratio of Diodrast; $C_{I n}=$ inulin clearance rate; $C_{D}=$ whole blood clearance of Diodrast, corrected * Abbreviations: $E_{D}=$ renal extraction ratio of Diodrast; $C_{I n}=$ inulin clearance rate;
for renal extraction; $U_{I_{n}}=$ urinary inulin concentration; $P_{I_{n}}=$ plasma inulin concentration.

† Dehydrated for 72 hours, anesthetized with ether, and injected with $1.0 \mathrm{ml}$ isotonic $\mathrm{NaCl}$ solution. 
terized just before the clearance study was begun. In these animals $5 \mathrm{ml}$ of isotonic saline was introduced into the peritoneal cavity before the incision was closed.

Clearance studies were performed as previously described (4), except that in most experiments urine was collected through a catheter introduced into the bladder via the urethra. Inulin and Diodrast- ${ }^{131} \mathrm{I}$ were administered as a priming dose and then by constant infusion for 35 to 40 minutes before starting the first collection period. In the majority of experiments, two clearance periods of 15 to 20 minutes' duration were performed. Blood was taken simultaneously from the renal vein catheter and from the tip of the tail several minutes before the midpoint of each period. Tail blood was used for determination of the renal extraction of Diodrast, since the blood level was stable and therefore equality between arterial and peripheral venous blood concentrations could be assumed. Counting for ${ }^{131} \mathrm{I}$ was performed on $0.1-\mathrm{ml}$ samples of whole blood from the renal vein and tail. At the end of the last clearance period a third set of blood samples was taken from the renal vein and tail for ${ }^{131} \mathrm{I}$ counting, thus providing an additional check on the constancy of the extraction ratio.

The in vivo accumulation of Diodrast in the renal cortex was evaluated in a series of control rats and animals injected with hemoglobin. Immediately after the final collection of blood the right kidney was removed and frozen in dry ice and acetone. Pieces of cortex were cut from the frozen tissue, weighed, and counted. The activity was compared to that in tail blood taken just before nephrectomy.

Diodrast- ${ }^{131} \mathrm{I}$ in whole blood and diluted urine was counted in a Packard autogamma spectrometer. Other analytical methods have been previously described (4).

\section{Results}

\section{Clearance studies in control animals}

Measurements of inulin and Diodrast clearances were performed in 11 normal rats, in which a renal vein catheter had been implanted 3 to 7 days previously. These data are summarized in Table I. The inulin clearance values in this group closely approximate those reported previously (4) in normal, nonoperated animals (0.850 $\mathrm{ml}$ per minute per $100 \mathrm{~g})$. Data from two additional groups of control animals are also shown in Table I. These rats were handled in a fashion identical to those injected with hemoglobin, except that they were injected with $1.0 \mathrm{ml}$ isotonic $\mathrm{NaCl}$ solution during ether anesthesia rather than with a solution of hemoglobin. They had been dehydrated 72 hours before injection, and renal vein catheter placement was performed under pentobarbital anesthesia just before initiation of the clearance study. Clearance measurements were made at either 3 to 5 hours or 24 hours after saline injection, corresponding to the time of study of hemoglobin-injected rats. Mean inulin clearance rates were slightly lower in these two groups than in the normal rats, but the difference is not statistically significant. Calculated renal blood flow and renal extraction of Diodrast $\left(E_{D}\right)$ were not significantly affected. Although there was a moderate degree of individual variation in inulin and Diodrast clearance in all three groups, $\mathrm{E}_{\mathrm{D}}$ was relatively constant. The range, in the 29 animals of the three groups, was 0.460 to 0.630 .

\section{Effects of hemoglobin injection on renal function}

Studies 3 to 6 hours after hemoglobin administration. Previous data have indicated that the renal lesion produced by hemoglobin injection has an abrupt onset (4). The state of renal perfusion in this initial stage of the lesion has been investigated in the present experiments.

A low renal blood flow was present in all animals manifesting a marked reduction of inulin clearance at 3 to 6 hours after hemoglobin injection. This is shown in Figure 1, which includes data from 11 rats in which the inulin clearance was less than $0.2 \mathrm{ml}$ per minute per $100 \mathrm{~g}$. There appears to be a significant correlation between renal blood flow and inulin clearance rate in this group of animals $(r=0.78)$. The mean data from this group are given in Table II. $E_{\mathbf{D}}$ was

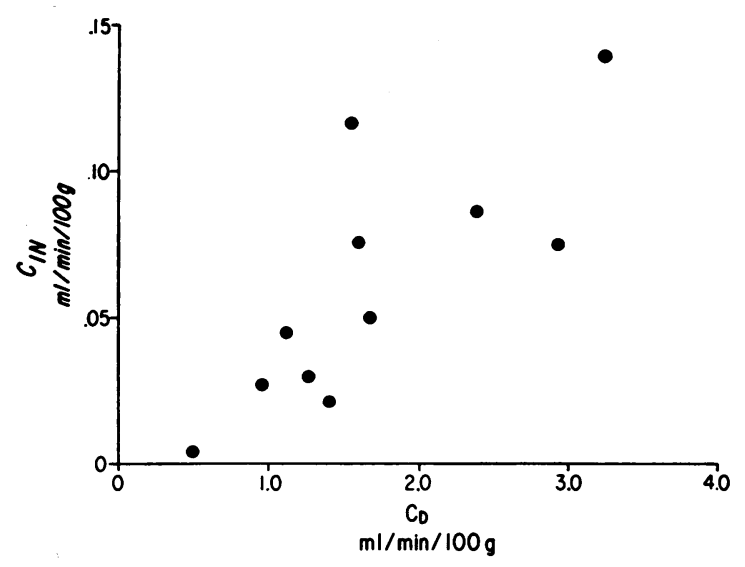

Fig. 1. Relationship of INULIN Clearance rate to RENAL BLOOD FLOW 3 TO 6 HOURS AFTER HEMOGLOBIN INJECTION. $C_{\text {In }}=$ inulin clearance rate; $C_{D}=$ whole blood clearance of Diodrast, corrected for renal extraction. 
TABLE II

Renal functions 3 to 6 and 24 hours after hemoglobin injection

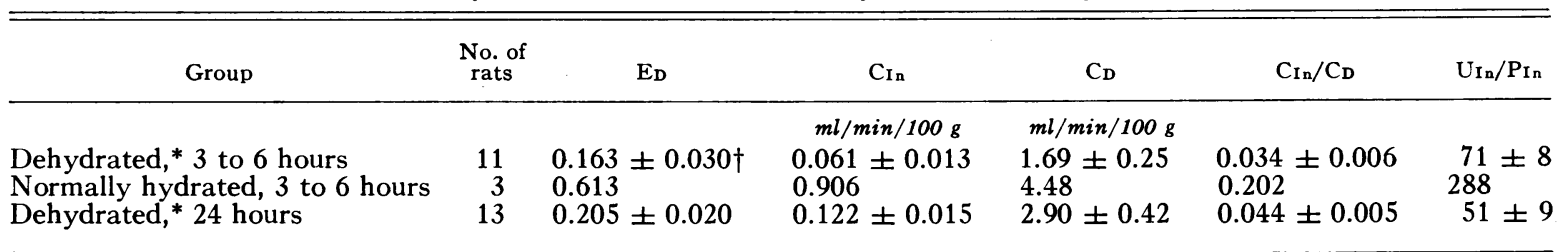

* Includes all animals studied at each time period with $C_{I_{n}}$ less than $0.2 \mathrm{ml}$ per minute per $100 \mathrm{~g}$.

$\dagger$ Values are means, in the dehydrated rats, \pm standard errors.

consistently depressed, to less than 0.2 in nine of 11 rats, and significantly lower than in the comparable saline-injected control group (Table I). The ratio of inulin clearance to renal blood flow and the urine to plasma inulin concentration ratio were also consistently and significantly depressed below the control values.

These functional changes are specific for animals that develop an acute renal lesion after hemoglobin injection. Nondehydrated rats injected with hemoglobin under otherwise identical conditions showed no depression of $E_{D}$, inulin clearance $\left(C_{I n}\right)$, renal blood flow, the ratio of inulin to Diodrast clearance, or the urine to plasma ratio of inulin. Mean data from three such experiments are shown in Table II.

Renal functions 24 hours after hemoglobin injection. Serial determinations of inulin clearance rate in individual rats have previously demonstrated that the functional defect observed at 3 to 6 hours after hemoglobin injection persists to 24 hours (4), although in some animals inulin clearance does increase during this time interval. The relationship between renal blood flow and inulin clearance rate in animals studied 24 hours after hemoglobin injection is shown in Figure 2 . Blood flow was below normal in the majority of rats, but not so consistently as in animals studied several hours after onset of the lesion (Figure 1). There was a significant correlation between inulin and Diodrast clearances $(p=<0.01)$. Blood flow was normal or near normal in rats in which inulin clearance exceeded $0.3 \mathrm{ml}$ per minute per $100 \mathrm{~g}$. In contrast, renal blood flow ranged from markedly depressed to normal values in rats with an inulin clearance rate of less than $0.2 \mathrm{ml}$ per minute per $100 \mathrm{~g}$, indicating the coexistence of normal perfusion and severe depression of excretory function in some animals. Mean values for the latter group are shown in Table II. As in rats studied at the earlier time, Diodrast extraction, $C_{I n} / C_{D}$, and urinary/plasma $(U / P)$ inulin were consistently and significantly reduced below the values for the comparable control group (Table I). Although mean blood flow was reduced below the control value, because of the wide range of values observed this difference does not assume statistical significance $(0.10>p>$ $0.05)$.

Renal function at 3 and 7 days after hemoglobin injection. Previous studies indicated that between 24 and 72 hours after hemoglobin injection a marked increase in inulin clearance rate occurs (4). An apparent further increment was observed between 3 and 7 days, although restoration to normal values did not occur. Sixteen rats were studied in the present experiments, eight at 3 days and eight at 7 days after inception of the lesion. The data are summarized in Table III and Figure 3. The mean inulin clearance rates agree closely with previous data (4). At 3 days,

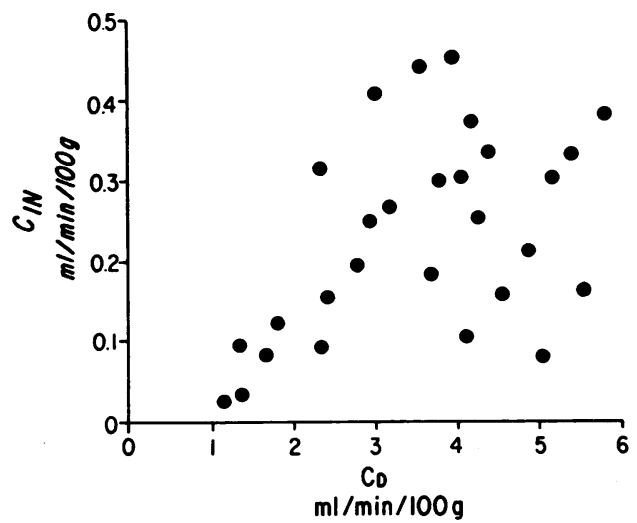

Fig. 2. Relationship of inUlin Clearance Rate to RENAL BLOOD FLOW 24 HOURS AFTER HEMOGLOBIN INJECTION. Observations on animals with lesions of varying degrees of severity. 


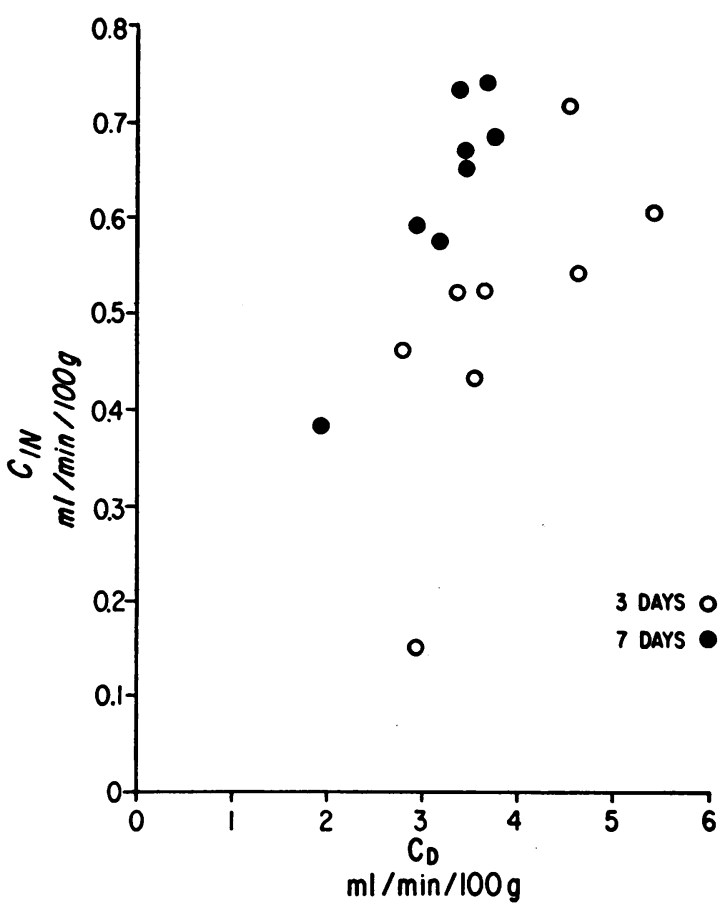

Fig. 3. RELAtionship of inUlin Clearance RAte AND RENAL BLOOD FLOW 3 AND 7 DAYS AFTER HEMOGLOBIN INJECTION.

renal blood flow closely approximated the normal value. Inulin clearance was significantly depressed, as were $C_{I n} / C_{D}$ and $U / P$ inulin. $E_{D}$ was slightly lower than normal, but the difference was not significant statistically $(0.10>p>0.05)$. At 7 days after hemoglobin injection, mean inulin clearance had risen, but it remained significantly lower than normal. Mean renal blood flow was also significantly less than the normal mean, and, as shown in Figure 3, it was below $4.0 \mathrm{ml}$ per minute per $100 \mathrm{~g}$ in all animals in this group. $\mathrm{E}_{\mathrm{D}}, \mathrm{C}_{\mathrm{In}} / \mathrm{C}_{\mathrm{D}}$, and $\mathrm{U} / \mathrm{P}$ inulin were all restored to normal at 7 days. The data at 7 days suggest that there has been a loss of renal mass, with residual nephrons functioning in a normal fashion, as evidenced by normal $E_{D}$, ratio of inulin clear- ance to blood flow, and ability to concentrate inulin in the urine. The possibility that a permanent reduction in functioning renal mass is produced by this experimental lesion is raised, but remains to be more fully explored.

\section{Effects of volume expansion on renal clearance in rats with a renal lesion}

To evaluate the influence of renal ischemia on the excretory defect observed in the initial phase of this renal lesion, we produced volume expansion in rats with an established lesion at 3 to 4 hours after hemoglobin administration. This was achieved by intravenous loading with either a $20 \%$ mannitol solution, $1.0 \mathrm{ml}$ per $100 \mathrm{~g}$ body weight, or a $5 \%$ solution of mannitol in isotonic saline, $3.0 \mathrm{ml}$ per $100 \mathrm{~g}$. In each experiment one control clearance was performed just before volume expansion, and in the majority of experiments two additional periods starting 30 to 40 minutes after fluid administration were observed. Although in some animals this produced no marked effect on renal clearances, in others a substantial increase in renal blood flow was observed. Data from the latter group are shown in Table IV. In all animals but one (rat 813) renal blood flow was restored to normal after fluid administration. Despite this, although inulin clearance rates rose in four of the six rats, including one which was essentially anuric during the control period, in all animals $\mathrm{C}_{\text {In }}$ remained appreciably depressed below the normal value. The extraction ratio of Diodrast fell in all rats. In three animals the rise in renal blood flow was effected without an increase in the uncorrected clearance rate of Diodrast, whereas two rats (779 and 872) showed an increased calculated renal blood flow as a result both of decreased $E_{D}$ and increased uncorrected $C_{D}$. These same animals showed the most pronounced rise in inulin clearance rate after volume expansion, although in neither case

TABLE III

Renal functions 3 and 7 days after hemoglobin administration

\begin{tabular}{|c|c|c|c|c|c|c|}
\hline $\begin{array}{c}\text { Time after } \\
\text { hemoglobin injection }\end{array}$ & $\begin{array}{l}\text { No. of } \\
\text { rats }\end{array}$ & ED & $C_{I_{n}}$ & $C_{D}$ & $\mathrm{C}_{I_{n} / \mathrm{CD}_{\mathrm{D}}}$ & $\mathrm{UI}_{\mathrm{In}} / \mathrm{PIn}_{\mathrm{In}}$ \\
\hline days & & & $\mathrm{ml} / \mathrm{min} / 100 \mathrm{~g}$ & $\mathrm{ml} / \mathrm{min} / 100 \mathrm{~g}$ & & \\
\hline $\begin{array}{l}3 \\
7\end{array}$ & $\begin{array}{l}8 \\
8\end{array}$ & $\begin{array}{l}0.483 \pm 0.030 \\
0.575 \pm 0.013\end{array}$ & $\begin{array}{l}0.498 \pm 0.058 \\
0.632 \pm 0.041\end{array}$ & $\begin{array}{l}3.85 \pm 0.32 \\
3.22 \pm 0.20\end{array}$ & $\begin{array}{l}0.129 \pm 0.013 \\
0.198 \pm 0.004\end{array}$ & $\begin{array}{l}188 \pm 25 \\
301 \pm 30\end{array}$ \\
\hline
\end{tabular}


TABLE IV

Effects of volume expansion on renal functions after establishment of an acute renal lesion*

\begin{tabular}{|c|c|c|c|c|c|c|c|c|c|}
\hline \multirow[b]{2}{*}{ Rat no. } & \multicolumn{4}{|c|}{ Before volume expansion } & & \multicolumn{4}{|c|}{ After volume expansion } \\
\hline & $\mathrm{V} \dagger$ & $\mathrm{C}_{\text {In }}$ & $C_{D}$ & $E_{D}$ & & $\mathrm{~V}$ & $\mathrm{C}_{\mathrm{In}}$ & $C_{D}$ & $E_{D}$ \\
\hline & $\mu l / \min$ & \multicolumn{2}{|c|}{$\mathrm{ml} / \mathrm{min} / 100 \mathrm{~g}$} & & & $\mu l / \min$ & \multicolumn{2}{|c|}{$\mathrm{ml} / \mathrm{min} / 100 \mathrm{~g}$} & \\
\hline $\begin{array}{l}779 \\
790 \\
813 \\
816 \ddagger \\
867 \\
872\end{array}$ & $\begin{array}{l}0.56 \\
1.89 \\
1.23 \\
3.33 \\
0.95\end{array}$ & $\begin{array}{c}0.024 \\
0.167 \\
0.032 \\
\text { Virtua } \\
0.297 \\
0.036\end{array}$ & $\begin{array}{c}1.38 \\
2.48 \\
1.74 \\
\text { nuric } \\
2.85 \\
0.82\end{array}$ & $\begin{array}{l}0.092 \\
0.307 \\
0.179 \\
0.321 \\
0.270\end{array}$ & $\cdot$ & $\begin{array}{l}14.68 \\
27.34 \\
10.07 \\
53.84 \\
25.92 \\
64.78\end{array}$ & $\begin{array}{l}0.041 \\
0.142 \\
0.043 \\
0.117 \\
0.265 \\
0.166\end{array}$ & $\begin{array}{l}5.36 \\
8.07 \\
3.06 \\
4.29 \\
5.40 \\
5.28\end{array}$ & $\begin{array}{l}0.039 \\
0.077 \\
0.091 \\
0.148 \\
0.150 \\
0.179\end{array}$ \\
\hline
\end{tabular}

* Data from animals in which renal blood flow increased markedly after fluid administration.

$+\mathrm{V}=$ volume.

$\ddagger$ Received two injections of mannitol.

did inulin clearance rise proportionately as much as did renal blood flow.

The effect of mannitol administration on calculated renal blood flow cannot be attributed to a simple washout of Diodrast that has accumulated within the renal tubules, since, as noted above, in several animals uncorrected Diodrast clearance was not increased during diuresis. In all studies, solute diuresis had been established for at least 30 minutes before clearance measurements were made, thus obviating the effect of a rapidly rising urine flow on clearance values.

\section{In vivo accumulation of Diodrast in the renal cortex}

Slices of renal cortex were removed at the end of clearance studies and counted for ${ }^{131} \mathrm{I}$; the activity was compared to that in whole blood drawn immediately before nephrectomy. Results are expressed as the tissue/blood (T/B) ratio, where tissue activity is in counts per minute per gram and blood activity is in counts per minute per milliliter. The normal $\mathrm{T} / \mathrm{B}$ ratio, obtained from 12 normal and saline control animals, was $4.5 \pm 0.5$ (SE).

All rats with a significant renal lesion manifested a marked increase in $T / B$ at 3 to 6 hours and at 24 hours after hemoglobin injection. Elevation persisted at 3 and 7 days. At 7 days the difference from the normal group was small but significant $(p=<0.01)$. Values for rats with the most severe lesions $\left(\mathrm{C}_{\text {In }}=<0.2 \mathrm{ml}\right.$ per minute per $100 \mathrm{~g}$ ) at 3 to 6 hours and at 24 hours and from all animals studied at 3 and 7 days are summarized in Table V. In Figure 4 the $\mathrm{T} / \mathrm{B}$ ratios from rats with lesions of varying severity 24 hours after hemoglobin are plotted against inulin clearance rates. This reveals no simple relationship between these variables. Animals with the most profound depression of inulin clearance (less than $0.05 \mathrm{ml}$ per minute per 100 g) had lower $\mathrm{T} / \mathrm{B}$ ratios than those with clearances between 0.1 and $0.2 \mathrm{ml}$ per minute, whereas as clearance values rose further the $T / B$ ratio tended to diminish. In none of the four groups studied was there a significant correlation between $\mathrm{C}_{\text {In }}$ and $\mathrm{T} / \mathrm{B}$ ratio.

Ureteral obstruction in the rat produces a pattern of cortical accumulation of Diodrast similar to that observed in animals with a hemoglobinemic renal lesion. Unilateral ligation of the ureter was performed in nine rats. In five an infusion of Diodrast was started immediately thereafter, and the kidneys were removed 65 to 80 minutes later. In four rats Diodrast infusion and subsequent nephrectomy were performed 24 hours after ureteral ligation. The mean $\mathrm{T} / \mathrm{B}$ ratios were 56.1 and $49.1,65$ to 80 minutes and 24 hours after obstruction, respectively. The $\mathrm{T} / \mathrm{B}$ ratios in the

TABLE V

Tissue to blood ratios of Diodrast-131I in rats at various time intervals after hemoglobin injection

\begin{tabular}{|c|c|c|c|c|}
\hline $\begin{array}{l}\text { Time after hemoglobin } \\
\text { administration }\end{array}$ & $\begin{array}{l}\text { No. of } \\
\text { rats }\end{array}$ & $\mathrm{CIn}_{\mathrm{n}}$ & $C_{D}$ & $\begin{array}{l}\text { Tissue/blood } \\
\text { ratio }\end{array}$ \\
\hline & \multicolumn{4}{|c|}{$\mathrm{ml} / \mathrm{min} / 100 \mathrm{~g}$} \\
\hline $\begin{array}{l}3-6 \text { hours* } \\
24 \text { hours* } \\
3 \text { days } \\
7 \text { days }\end{array}$ & $\begin{array}{r}9 \\
10 \\
8 \\
8\end{array}$ & $\begin{array}{l}0.069 \dagger \\
0.123 \\
0.498 \\
0.632\end{array}$ & $\begin{array}{l}1.89 \\
2.67 \\
3.85 \\
3.22\end{array}$ & $\begin{array}{r}36.9 \pm 2.5 \ddagger \\
29.5 \pm 2.7 \\
19.7 \pm 2.0 \\
7.7 \pm 1.2\end{array}$ \\
\hline
\end{tabular}

* Includes only rats with $\mathrm{C}_{\mathrm{In}}$ less than $0.2 \mathrm{ml}$ per minute per $100 \mathrm{~g}$.

$\dagger$ Mean value.

$\ddagger$ Mean \pm standard error. 


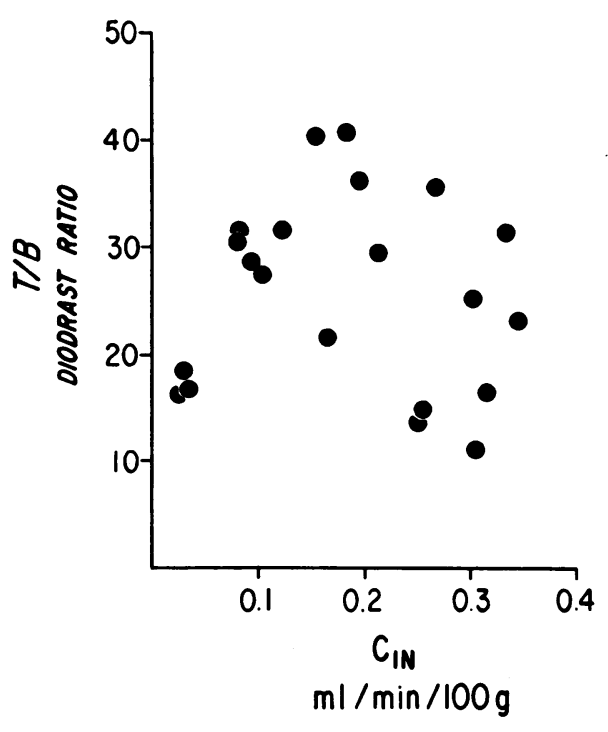

Fig. 4. Relationship of RENAL CORTICAL tissue to BLOOD RATIO OF DIODRAST 24 HOURS AFTER HEMOGLOBIN INJECTION TO INULIN CLEARANCE RATE.

contralateral control kidneys did not exceed those in normal rats.

The possibility that intrarenal accumulation of Diodrast affects the estimation of renal blood flow by the direct Fick method has been considered. The data indicate that when clearance measurements were made, net accumulation of Diodrast in the kidney had ceased. This is evidenced by the stable renal extraction ratios for Diodrast throughout each clearance study. If Diodrast were being accumulated during this period, a declining extraction ratio would be anticipated as the $\mathrm{T} / \mathrm{B}$ ratio approached a maximal value.

\section{Discussion}

The present data permit an evaluation of the role of renal ischemia in the initial development and subsequent evolution of the renal functional defect produced by the intravenous injection of hemoglobin. Renal blood flow is significantly and consistently reduced during the initial hours of this lesion. This appears to be a prolongation of the ischemic state, induced by water deprivation and ether anesthesia, that is necessary to the initial production of the lesion (4). This ischemic state is a transitory one, however, unless a characteristic renal lesion supervenes, as evidenced by normal values for renal blood flow in saline-injected animals 3 to 5 hours after anes- thesia and in normally hydrated rats injected with hemoglobin. The explanation for the reduction in renal perfusion in rats with an acute renal lesion is not evident from the present studies. The presence of apparently aggregated hemoglobin within the small vessels of the involved kidneys, persisting after hemoglobin has disappeared from the circulating plasma, has previously been described (5). The present data support the earlier hypothesis (5), based on this morphological evidence, that perfusion is impaired in the early stages of this lesion, but they fail to indicate whether intravascular aggregation of hemoglobin is a cause of the renal ischemia or merely a secondary effect of reduced flow through certain intrarenal vessels, induced by some other mechanism associated with this experimental preparation.

The data indicate that once the renal lesion has become established, although renal ischemia may contribute to the observed reduction in inulin clearance rate, it is not the primary cause of the failure of excretory function. There are several lines of evidence to support this. If renal ischemia were primarily responsible for the low inulin clearance rate, restoration of blood flow to a normal level should similarly restore inulin clearance. This is not the case. Plasma and extracellular fluid volume expansion may restore a normal blood flow during the initial hours after hemoglobin injection. In some rats this results in a moderate increase in inulin clearance rate, but it remains markedly depressed from the normal level. At 24 hours after hemoglobin administration some animals manifest a severe depression of inulin clearance rate despite a normal or near normal rate of blood flow, and at 72 hours significant depression of mean inulin clearance and a normal mean renal blood flow coexist. Furthermore, the functional pattern differs from that seen in experimentally produced renal ischemia $(6,7)$. A reduction in the tubular extraction of Diodrast is a constant feature of this lesion. In contrast, experimentally produced renal ischemia is not associated with a fall in tubular extraction ratio until virtually complete cessation of blood flow is achieved (7).

It seems reasonable to assume that those affected rats manifesting a normal renal blood flow at 24 hours would have shown renal ischemia if 
studied at 3 to 6 hours after onset of the lesion, since ischemia was a constant finding at that time in all animals with a markedly depressed inulin clearance rate. It therefore appears that restoration of blood flow was a part of the recovery process, occurring at a more rapid rate in this group than in those rats with ischemia persisting to 24 hours. The possibility exists that the type and extent of renal involvement differed in these two groups. Examination of histological sections does suggest more severe and widespread hemoglobin aggregation in the intrarenal vessels of the ischemic group at 24 hours. This is, however, a qualitative assessment based on a relatively small number of animals and can therefore not be considered a conclusive finding. In any event, although the excretory defect cannot be explained primarily on the basis of reduced renal blood flow, the sequence of changes during recovery suggests that the ultimate reversal of the fundamental lesion is dependent on restoration of normal renal perfusion.

The functional and morphological evidence from this and previous studies from this laboratory supports the view that the major factor responsible for excretory failure of the involved kidney is obstruction of tubular flow by intraluminal precipitation of hemoglobin. Morphologically there are two observations that tend to support this view, although the lack of quantification of these observations renders any attempted correlation with functional data necessarily tentative. Resolution of hemoglobin casts and restoration of the inulin clearance rate appear to be associated temporally. The most marked changes in each occur between 24 and 72 hours after onset of the lesion. Secondly, the presence of grossly dilated tubules suggests the presence of tubular obstruction (5). Absence of dilatation during the initial hours of the lesion (5), when renal blood flow is low, suggests that ischemia, perhaps most pronounced in obstructed nephrons, sufficiently reduces filtration pressure so that effective filtration in obstructed nephrons is halted at a relatively low intratubular hydrostatic pressure, insufficient to produce gross dilatation on histological examination. Tubular dilatation can, however, be produced at this stage of the lesion by the infusion of mannitol. It is not known whether this is an osmotic effect or one due to an increase in renal blood flow and filtration pressure, but the observation lends further support to the concept that obstruction by casts does impede nephron function.

A low renal extraction ratio of Diodrast is a constant feature of this renal lesion. This might be attributed to a metabolic defect in the proximal tubules, secondary to cellular damage. However, the data indicate marked cortical accumulation of Diodrast, a finding in direct contrast to the failure of renal uptake of Diodrast observed when proximal tubular necrosis is produced experimentally (8). This does not exclude the possibility that uptake of Diodrast is impaired in some proximal tubules, but it does indicate that in much of the renal cortex the capacity to take up Diodrast is preserved. Net uptake presumably ceases ultimately because excretion is impaired by diminished tubular flow (9). The latter may result from either obstruction to flow within tubules or diminished glomerular perfusion and filtration. The lack of correlation between renal blood flow and the $\mathrm{T} / \mathrm{B}$ ratio of Diodrast indicates that reduced perfusion alone does not account for the cortical accumulation of Diodrast, but reduced filtration rate secondary to some other undefined cause cannot be excluded as a contributory factor. The over-all lack of correlation between inulin clearance rate and $\mathrm{T} / \mathrm{B}$ Diodrast indicates that factors such as reduced perfusion of selected areas of the cortex and damage to proximal tubules in certain areas may be influencing the cortical uptake of Diodrast in obstructed or nonfunctioning nephrons, since, if such factors were not operative and if the sole functional defect were tubular obstruction, a close relationship between inulin clearance and $\mathrm{T} / \mathrm{B}$ Diodrast would be anticipated.

The present data appear to be at variance with certain other studies of acute renal failure associated with hemoglobinemia, particularly with respect to the roles of renal ischemia and tubular obstruction in the initial pathogenesis and in the subsequent stage of excretory failure. Goldberg observed no significant fall in renal blood flow after intra-aortic infusion of hemoglobin in the $\operatorname{dog}(3)$, although urine flows and creatinine clearances diminished markedly in most animals. However, Goldberg observed little change in $p$ aminohippurate extraction and a rise in urine to 
plasma creatinine concentration ratios, a functional pattern quite different from that observed in the present study. Although both studies emphasize the role of tubular obstruction in the etiology of the excretory defect, these discrepancies in the functional pattern suggest that different renal lesions were produced and that the two studies are therefore not strictly comparable. Harrison, Bunting, Ordway, and Albrink found no change in renal blood flow after methemoglobin injection in the dog, although urine flow, creatinine clearance rate, and urine to plasma creatinine ratios fell significantly (10). However, their study, as well as that of Bing (11), indicates that methemoglobin is more toxic to the kidney than a comparable amount of hemoglobin, and it has not yet been established that identical lesions are produced by these two pigments. Both the study of Goldberg (3) and that of Harrison and coworkers (10) were comparable in that renal blood flow in their dogs was essentially normal just before pigment injection, in contrast to the present set of experiments in which renal ischemia appeared to be a necessary predisposing factor to the production of a lesion. Harrison and co-workers were able to produce a renal lesion with the injection of hemoglobin, but only when a plasma concentration of at least $5 \mathrm{~g}$ per 100 $\mathrm{ml}$ was attained, in contrast to the present study, in which plasma hemoglobin concentration was less than $1.0 \mathrm{~g}$ per $100 \mathrm{ml}$ (4). These observations indicate that the state of renal perfusion at the time of hemoglobin injection is an important determinant of subsequent changes in renal function and may influence qualitatively the nature of the lesion produced.

Oken, Arce, and Wilson have reported micropuncture studies of the lesion produced in rats by the intramuscular injection of glycerol (2). They concluded that tubular obstruction was not a factor in the pathogenesis of the observed decrease in inulin clearance rates in individual nephrons, since intraluminal hydrostatic pressure was below normal in the affected tubules. Renal blood flow was not measured, but by direct observation apparent ischemia was present during the initial few hours after glycerol injection. Thereafter, peritubular capillary circulation appeared normal. Their conclusions that neither tubular obstruction nor renal ischemia was a causative factor in the renal excretory defect are apparently at variance with those of the present study. However, it seems probable that these are not qualitatively identical renal lesions. Pathologically, the glycerol-induced lesion is characterized by extensive necrosis of proximal tubular epithelium (12), whereas in the present experimental lesion necrosis is rarely present, and then only in widely scattered foci within the cortex. Furthermore, the studies of Finckh (13) question the role of blood pigments in the genesis of the glycerol-induced lesion. $\mathrm{He}$ found that intraperitoneally administered glycerol failed to produce hemoglobinuria, yet it evoked a renal lesion identical histologically to that after glycerol injection by the subcutaneous or intramuscular routes. This question remains unresolved, however, since Carroll, Kovács, and Tapp (14), using a larger dose of glycerol than that given by Finckh (13), did note hemoglobinuria associated with the renal lesion that followed intraperitoneal injection of glycerol. In any event, the lesion after glycerol injection appears to resemble morphologically that produced by nephrotoxic substances (15), and Oken and his co-workers have noted identical functional changes in that lesion and the one produced by mercury in the rat $(1,2)$.

These observations emphasize the difficulties in comparing the functional effects of experimental lesions when these are not produced by identical means. Which, if any, of these experimentally induced lesions more closely resembles the naturally occurring syndrome in man remains undetermined.

\section{Acknowledgment}

The author is grateful to Miss Shirley Hendershot for her able technical assistance.

\section{References}

1. Flanigan, W. J., and D. E. Oken. Renal micropunsture study of the development of anuria in the rat with mercury-induced acute renal failure. J. clin. Invest. 1965, 44, 449 .

2. Oken, D. E., M. L. Arce, and D. R. Wilson. Glycerol-induced hemoglobinuric acute renal failure in the rat. I. Micropuncture study of the development of oliguria. J. clin. Invest. 1966, 45, 724.

3. Goldberg, M. Studies of the acute renal effects of hemolyzed red blood cells in dogs including esti- 
mations of renal blood flow with krypton ${ }^{85} \mathrm{~J}$. clin. Invest. 1962, 41, 2112.

4. Jaenike, J. R. The renal lesion associated with hemoglobinemia. I. Its production and functional evolution in the rat. J. exp. Med. 1966, 123, 523.

5. Jaenike, J. R., and E. E. Schneeberger. The renal lesion associated with hemoglobinemia. II. Its structural characteristics in the rat. J. exp. Med. 1966, 123, 537.

6. Brodwall, E. K. Renal extraction of PAH in uncomplicated circulatory failure and during hypoxia. Scand. J. clin. Lab. Invest. 1964, 16, 6.

7. Phillips, R. A., V. P. Dole, P. B. Hamilton, K. Emerson, Jr., R. M. Archibald, and D. D. Van Slyke. Effects of acute hemorrhagic and traumatic shock on renal function of dogs. Amer. J. Physiol. 1946, $145,314$.

8. Josephson, B., and J. Kallas. Iodine concentration in rabbit kidneys after Diodrast injection. Mechanism of renal tubular excretion. Amer. J. Physiol. 1953, 174, 65.

9. Deetjen, P., and H. Sonnenberg. Der tubuläre Transport von p-Aminohippursäure. Mikroperfu- sionsversuche am Einzelnephron der Rattenniere in situ. Pflügers Arch. ges. Physiol. 1965, 285, 35.

10. Harrison, H. E., H. Bunting, N. K. Ordway, and W. S. Albrink. The pathogenesis of the renal injury produced in the dog by hemoglobin or methemoglobin. J. exp. Med. 1947, 86, 339.

11. Bing, R. J. The effect of hemoglobin and related pigments on renal functions of the normal and acidotic dog. Bull. Johns Hopk. Hosp. 1944, 74, 161.

12. Finckh, E. S. Experimental acute tubular nephrosis following subcutaneous injection of glycerol. J. Path. Bact. 1957, 73, 69.

13. Finckh, E. S. The indirect action of subcutaneous injections of glycerol on the renal tubules in the rat. J. Path. Bact. 1959, 78, 197.

14. Carroll, R., K. Kovács, and E. Tapp. The pathogenesis of glycerol-induced renal tubular necrosis. J. Path. Bact. 1965, 89, 573.

15. Oliver, J., M. MacDowell, and A. Tracy. The pathogenesis of acute renal failure associated with traumatic and toxic injury. Renal ischemia, nephrotoxic damage and the ischemuric episode. $\mathrm{J}$. clin. Invest. 1951, 30, 1305. 